As garantias constitucionais das pessoas com deficiência à luz do Código de Defesa do \title{
Consumidor
}

Isaac Nilson Fonseca Dias

Rosélia Araújo Rodrigues dos Santos 


\section{As garantias constitucionais das pessoas com deficiência à luz do Código de Defesa do Consumidor}

\section{The constitutional guarantees of disabled people in the light of the consumer defense code}

Isaac Nilson Fonseca Dias ${ }^{1}$; Rosélia Araújo Rodrigues dos Santos ${ }^{2}$

\section{Resumo}

O presente artigo científico tem o objetivo de esclarecer os consumidores com deficiência física, visual, auditiva, mental e/ou múltipla acerca das garantias previstas na Constituição da República Federativa do Brasil de 1988, perante a Lei Federal $n^{\circ} 8.078 / 90$, o denominado Código de Defesa do Consumidor. No intuito de melhor elaborar o trabalho em deslinde, pauta-se diante de uma pesquisa bibliográfica e a explanação dos diversos entendimentos jurisprudenciais sobre o assunto. Desse modo, inicialmente, evidenciam-se os princípios da dignidade da pessoa humana e da isonomia, destacando o que há de mais relevante e esclarecedor ao estudo. Após, salienta-se a efetiva aplicação das normas protetivas aos portadores de necessidades especiais, na medida em que se vislumbram as dificuldades em guarnecer os direitos e garantias das pessoas com deficiência.

Palavras-chave: Pessoas com deficiência; Garantias constitucionais; Direito do consumidor.

\section{Abstract}

The current paper has the objective of clarify the guarantees disposed on Brazil Federative Republic 1988 Constitution to the consumers with physical, visual, hearing, mental and/or multiple disabilities according to the Federal Law 8.078/90, the titled Consumer Defense Code. In order to elaborate better the current paper, a bibliographic research and the explanation of the diverse jurisprudential understandings about the content are shown below. Therefore, initially, fundamental principles of human dignity and isonomy, evidenced highlighting what is the most relevant and clarifying to the paper. Then, the disabled people's protective laws effective application is stood out while the difficulties to protect the disabled people's 1 Acadêmico do Curso de Direito da Universidade Ceuma, campus Renascença, do $9^{\circ}$ período noturno. Acadêmico do Curso de Filosofia da Universidade Federal do Maranhão. Email: isaac_nfd@hotmail.com

2 Advogada. Professora na Universidade Ceuma. Especialista em Didática Universitária. Email: roseliaaraujo@bol.com.br 
rights and guarantees are analyzed.

Keywords: disabled people; constitutional guarantees; consumer law.

\section{Introdução}

Comenta-se, com frequência, a respeito dos direitos do consumidor e suas influências no cotidiano, uma vez que as relações de consumo são inerentes ao próprio convívio numa sociedade contemporânea pósindustrial.

Todavia, pouco se discute acerca da aplicabilidade e efetividade dos direitos do consumidor às pessoas com deficiência, seja no âmbito das instituições de ensino superior do curso de Direito ou por intermédio dos órgãos de proteção ao consumidor, razão pela qual inquestionável a necessidade de um estudo, a rigor, mais atencioso.

Desta forma, visando atender a interesses primordiais das pessoas com deficiência nas relações de consumo, como a igualdade, o respeito e a proteção, é que as disposições principiológicas e normativas da Carta Magna de 1988 se fazem úteis no presente estudo. As garantias fundamentais intrínsecas ao cidadão, assim como os princípios basilares da dignidade da pessoa humana e da igualdade, tornam-se imprescindíveis para avaliar a eficácia do modus operandi dos fornecedores quando o destinatário final de produtos ou serviços possui singular necessidade, decorrente de uma deficiência congênita.

Assim, não se limita o presente feito a ilustrar as relações entre os consumidores portadores de deficiência junto a fornecedores de produtos ou serviços, mas conjuntamente atestar as dificuldades de aplicação das normas protetivas aos cidadãos deficientes, diante do contexto constitucional.

\section{Dos Direitos e Garantias Fundamentais a Pessoa com Deficiência}

Primeiramente, cumpre salientar que a proposta do presente tópico é fazer uma análise dos mais importantes princípios constitucionais, delimitando sua aplicação ao estudo desenvolvido, tecendo breves considerações capazes de definir seu conteúdo e esclarecer sua relevância para as pessoas com deficiência nas relações de consumo, uma vez que não seria possível, em parcas considerações, analisar os diversos âmbitos de incidência dos referidos princípios.

Assim, feitas tais ressalvas, inicia-se o exame da matéria pelo macroprincípio da Dignidade da Pessoa Humana (artigo $1^{\circ}$, inciso III da Constituição Federal), princípio basilar não só do Direito Constitucional, mas de todo o ordenamento jurídico. O princípio da dignidade da pessoa 


\section{(

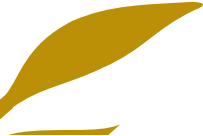

humana é apreciado como sendo um dos valores básicos inerentes ao ser humano. É pressuposto elementar de todos os demais direitos e liberdades que dispõem a Carta Constitucional.

Não obstante, defini-lo é a mais difícil tarefa existente no campo doutrinário. De acordo com Stolzen e Pamplona (2014, p. 49), "a noção jurídica de dignidade traduz um valor fundamental de respeito à existência humana, segundo as suas possibilidades e expectativas, patrimoniais e afetivas, indispensáveis à sua realização pessoal e à busca da felicidade."

Por outro lado, Silva (2002, p. 105) defende que "a dignidade da pessoa humana é um valor supremo que atrai o conteúdo de todos os direitos fundamentais do ser humano, desde o direito à vida." Igualmente, vale dizer que a dignidade:

É um valor espiritual e moral inerente à pessoa, que se manifesta singularmente na autodeterminação consciente e responsável da própria vida e que traz consigo a pretensão ao respeito por parte das demais pessoas, constituindo-se em um mínimo invulnerável que todo estatuto jurídico deve assegurar, de modo que, somente excepcionalmente, possam ser feitas limitações ao exercício dos direitos fundamentais, mas sempre sem menosprezar a necessária estima que merecem todas as pessoas enquanto seres humanos (MORAES, 2002, p. 128).

Daí, torna-se possível inferir que existe uma pluralidade de conceitos capazes de instituir uma rápida e inacabada noção do mencionado princípio, todavia, ainda assim, seu aproveitamento ao estudo em deslinde é de suma importância.

É justamente na essência da dignidade da pessoa humana que as pessoas com deficiência fundamentam o grau máximo de exercício de seus direitos, com a integral proteção dos entes estatais, no sentido de promoverem a efetiva integração e adaptação social. George Salomão acentua que:

Pessoas com deficiência e pessoas sem deficiência são todas dignas e merecedoras de igual respeito e consideração por parte do Estado e da comunidade. Todavia, os mecanismos de respeito e promoção da dignidade humana não são idênticos em se tratando de pessoas com ou sem deficiência. Temos, nesse caso, duas situações distintas que necessitam ser tratadas diferentemente para efeitos de concretização e promoção da dignidade da pessoa humana. (2012, p.69) 
O Estado não pode permanecer inerte, tampouco negligenciar as circunstâncias que afetam sobremaneira a dignidade da pessoa com deficiência, cabendo-lhe o poder-dever de empregar medidas adequadas, para que os valores sociais e fundamentais deste cidadão sejam preservados. No que concerne a este posicionamento, a Convenção sobre os Direitos das Pessoas com Deficiência estabelece que:

Artigo $1^{\circ}$. O propósito da presente convenção é promover, proteger e assegurar o exercício pleno e equitativo de todos os direitos humanos e liberdades fundamentais por todas as pessoas com deficiência e promover o respeito pela sua dignidade inerente. Pessoas com deficiência são aquelas que têm impedimentos de longo prazo de natureza física, mental, intelectual ou sensorial, os quais, em interação com diversas barreiras, podem obstruir sua participação plena e efetiva na sociedade em igualdades de condições com as demais pessoas. (BRASIL, Decreto $\mathrm{n}^{\circ}$ 6949, 2009, art. $\left.1^{\circ}\right)$.

Consoante o art. 10 da Lei $n^{\circ} 13.146$, de 6 de julho de 2015 (BRASIL, 2015), "compete ao poder público garantir a dignidade da pessoa com deficiência ao longo de toda a vida". Tal dispositivo revela que a sistemática de atuação do poder público é ampla, devendo a pessoa com deficiência ser resguardada em todas as áreas, inclusive com tratamento igual na área do consumidor.

Por isso, não se pode dissociar a necessidade de atuação estatal sem mencionar a relevância do princípio da igualdade na concretização dos direitos as pessoas com deficiência. Definem Mendes, Coelho e Branco que tal princípio:

Significa em resumo tratar igualmente os iguais e desigualmente os desiguais, na medida da sua desigualdade. Como, por outro lado, no texto da nossa Constituição, esse princípio é enunciado com referência à lei - todos são iguais perante a lei - alguns juristas construíram uma diferença, porque a consideram importante, entre a igualdade na lei e a igualdade diante da lei, a primeira tendo por destinatário precípuo o legislador, a quem seria vedado valer-se da lei para fazer discriminações entre pessoas que mereçam idêntico tratamento; a segunda, dirigida principalmente aos intérpretes/aplicadores da lei, impedir-lhes-ia de concretizar enunciados jurídicos dando tratamento 
distinto a quem a lei encarou como iguais. (2009, p.179)

A regra básica é a de que a aplicação do princípio da isonomia resultará a efetividade dos direitos da proteção e inclusão no seio da sociedade.

Alexsandro Rahbani Aragão Feijó (2002, p. 70) conclui que "só é possível entender o tema da proteção excepcional das pessoas portadoras de deficiência se a compreensão do princípio da igualdade for uma realidade, pois igualdade é a regra mestra e superior a todo o direito à inclusão social do portador e sempre estará presente na aplicação do direito".

Do mesmo modo, destaca Luiz Alberto David Araújo:

$\mathrm{O}$ direito à igualdade surge como regra de equilíbrio dos direitos das pessoas portadoras de deficiência. Toda e qualquer interpretação constitucional que se faça, deve passar, obrigatoriamente, pelo princípio da igualdade. Só é possível entendermos o tema da proteção excepcional das pessoas portadoras de deficiência se entendermos corretamente o princípio da igualdade. (ARAÚJO, 1997, p. 49)

No entanto, a incidência do referido princípio não está limitada ao seu propósito singular, podendo, inversamente ao que lhe é intrínseco, incidir na própria quebra do direito de igualdade, isto é, na exata desigualdade, desde que o caso concreto coerentemente permita, sendo assim, capaz de evitar que as distinções do direito positivado acarretem injustiças aos considerados desiguais.

À vista disso, Araújo entende que:

A igualdade, desta forma, deve ser a regra mestra de aplicação de todo o entendimento do direito à integração das pessoas portadoras de deficiência. É razoável entender-se que a pessoa portadora de deficiência tem, pela sua própria condição direito à quebra da igualdade, em situações das quais participe com pessoas sem deficiência. Assim sendo, o princípio da igualdade incidirá, permitindo a quebra da isonomia e protegendo a pessoa portadora de deficiência, desde que a situação logicamente o autorize (...). Da mesma forma, a igualdade será aplicada para impedir que a deficiência sirva de quebra do princípio isonômico, sem logicidade para tal descrímen. Trata-se, na realidade, da aplicação inversa do mesmo princípio acima enunciado. O candidato a concurso público portador de deficiência de locomoção, 
por exemplo, não pode ser vetado, apenas e tão-somente, em virtude de sua deficiência. Há de haver correlação lógica entre o cargo pretendido e a incapacidade. A igualdade, portanto, deve ser aplicada. (1997, p. 50)

Trata-se de exceção à regra, advinda da necessidade da Constituição Federal em guarnecer primordialmente o necessitado, a minoria hipossuficiente em relação à maioria autossuficente, objetivando, a partir dessa proteção, a igualdade e, consequentemente, a inclusão social das pessoas com deficiência.

O que cabe a ser delimitado pelo princípio da isonomia, adstrito as relações sociais em que participem as pessoas com deficiência, é que o objetivo basilar se revela na intenção do Estado em empreender o máximo de proteção possível ao portador de deficiência, seja aplicando a regra do princípio da igualdade ou sua exceção, pairando na desigualdade, igualmente apta de efetivar o direito protetivo.

Por esse motivo é que Feijó (2002, p. 71) defende o princípio da igualdade, compreende que "os direitos dos cidadãos são os mesmos, mas as condições para exercê-los não. Daí a importância do princípio da igualdade ser aplicado nos demais direitos expostos, a fim de proporcionar ao portador uma vida normal". Nessas circunstâncias, situam-se os direitos inerentes às relações de consumo.

\section{Das Pessoas com Deficiência nas Relações de Consumo}

Após transcender o caráter principiológico no plano teórico, é oportuno salientar, neste momento, sua aplicabilidade no plano empírico, enfocando as relações das pessoas com necessidades especiais no âmbito consumerista, demonstrando a efetividade das normas protetivas aos consumidores portadores de deficiência, bem como a problemática em assegurar os referidos direitos e garantias constitucionais.

As relações de consumo surgem através de um negócio jurídico compreendido entre duas ou mais pessoas, concebido através de princípios contratuais básicos. Segundo Rizzato Nunes (2005, p. 71), "haverá relação jurídica de consumo sempre que se puder identificar num dos pólos da relação o consumidor, no outro, o fornecedor, ambos transacionando produtos e serviços".

Com fulcro no Código de Defesa do Consumidor (BRASIL, Lei 8.078, 1990, art. $4^{\circ}$ ), a Política Nacional das Relações de Consumo tem como objetivo o atendimento das necessidades do consumidor e a defesa de sua dignidade, saúde e segurança, além da proteção do seu interesse econômico. 
Neste viés, a Ministra do Superior Tribunal de Justiça, Fátima Nancy Andrighi, acentua que:

[...] nas relações de consumo, o fornecimento de produtos

e serviços não pode se dar em detrimento da dignidade do homem-consumidor, sobretudo de seus direitos da personalidade, como o direito à honra, a um nome sem mácula, à intimidade, à integridade física, psíquica e à imagem, entre outros. (2008, p. 1.145)

Assim, cumpre salientar que, no momento em que as pessoas com deficiência integram as relações de consumo, os produtos e serviços disponibilizados em mercado devem se adaptar, quando possível, às necessidades e às limitações daqueles, resguardando sua qualidade e segurança, como se não adaptados fossem.

Sobre o tema,Waldir Macieira da Costa Filho exemplifica:

A pessoa com deficiência ao adquirir um equipamento ou dispositivo, ou mesmo contratar um serviço, essencial para sua autonomia e mobilidade, como uma cadeira de rodas, uma prótese auditiva, um automóvel adaptado, um software adaptado, um serviço particular de transporte acessível ou de reabilitação, tem a expectativa e a boa-fé de que aquele produto funcionará e/ou aquele serviço lhe proporcionará condições para realizar tarefas essenciais para sua vida, como trabalhar, estudar, divertir-se, comunicar-se, interagir com os demais da sociedade. (2012, p. 406)

E complementa tal pensamento concluindo:

Quando um produto não funciona adequadamente, ou o serviço não é realizado, ou o é de má qualidade, acarreta prejuízos e cria barreiras ao exercício pleno dos direitos da pessoa com deficiência, agravando sua situação discriminante na sociedade, necessitando de soluções imediatas para evitar situações constrangedoras e segregadoras a esses cidadãos. (2012, p. 406)

Em suma, cabe dizer que os fornecedores devem adequar seus empreendimentos às exigências do consumidor portador de deficiência, devendo, para tanto, adaptar seus estabelecimentos comerciais, modificar seus métodos de trabalho e o oferecimento de seus produtos e serviços, razão pela qual o mercado de consumo não pode manter-se indiferente quanto às dificuldades de conscientização destes fornecedores. 
Dentre os aludidos direitos que regem as relações de consumo, destaca-se o direito à informação. Especifica-se como direito básico do consumidor a informação adequada e clara sobre os diferentes produtos e serviços (BRASIL, Lei 8.078, 1990, art. 6º, inciso III).

Delibera Antonio Herman de Vasconcellos e Benjamim que:

A garantia de informação plena do consumidor (...) funciona em duas vias. Primeiro, o direito do consumidor busca assegurar que certas informações negativas (a 'má informação', porque inexata - digo algo que não é como na publicidade enganosa) não sejam utilizadas. Em segundo lugar, procura garantir que certas informações positivas (deixo de dizer algo que é, como, por exemplo, alertar sobre riscos do produto ou serviço) sejam efetivamente passadas ao consumidor. (2004, p. 90)

Desse modo, assegurar a efetiva informação ao consumidor quanto aos produtos e serviços disponibilizados em mercado permitirá, mesmo que em tese, que os demais direitos inerentes a relação de consumo possam ser exercidos com plenitude, impedir que o fornecedor se aproveite do status de superioridade e, por consequencia, atue de modo arbitrário em face do consumidor vulnerável.

No que diz respeito às pessoas com deficiência, a ausência de informação clara e precisa não só impede que as ofertas de produtos e serviços alcance estes consumidores em especial, como também compromete a liberdade de escolha e a independência em relação a terceiros, podendo fomentar à pessoa com deficiência um sentimento de desvalorização em detrimento dos outros consumidores em geral.

À vista disso, o aprimoramento legislativo afigura-se importante para que a pessoa com deficiência exerça efetivamente o seu direito à informação, o que se registra, em especial, pela vigência da Lei no 13.146/2015 (BRASIL, 2015, art. 69), que prevê:

Art. 69 - O poder público deve assegurar a disponibilidade de informações corretas e claras sobre os diferentes produtos e serviços ofertados, por quaisquer meios de comunicação empregados, inclusive em ambiente virtual, contendo a especificação correta de quantidade, qualidade, características, composição e preço, bem como sobre os eventuais riscos à saúde e à segurança do consumidor com deficiência, em caso de sua utilização, aplicando-se, no que couber, os arts. 30 a 41 da Lei no 8.078, de 11 de setembro de 1990. (BRASIL, 2015)

Outrossim, ainda por força da referida Lei n 13.146/2015 (BRASIL, 
2015, art. 100), foram alterados o artigo $6^{\circ}$ e o artigo 43, ambos do Código de Defesa do Consumidor, visando dar às pessoas com deficiência maior prioridade no tocante as informações veiculadas nas relações de consumo.

Desta feita, dispõe o art. $6^{\circ}$, inciso III e parágrafo único do CDC, in verbis:

Art. 6º- São direitos básicos do consumidor:

(...)

III - a informação adequada e clara sobre os diferentes produtos e serviços, com especificação correta de quantidade, características, composição, qualidade, tributos incidentes e preço, bem como sobre os riscos que apresentem.

\section{(...)}

Parágrafo único. A informação de que trata o inciso III do caput deste artigo deve ser acessível à pessoa com deficiência, observado o disposto em regulamento. (BRASIL, Lei 8.078, 1990) (grifo nosso)

$\mathrm{O}$ art. 43 do Código de Defesa do Consumidor determina o acesso do consumidor às informações registradas em sistemas cadastrais de consumidores, nos seguintes moldes:

Art. 43 - O consumidor, sem prejuízo do disposto no art. 86 , terá acesso às informações existentes em cadastros, fichas, registros e dados pessoais e de consumo arquivado sobre ele, bem como sobre as suas respectivas fontes.

[...]

$\S 6^{\circ}$ Todas as informações de que trata o caput deste artigo devem ser disponibilizadas em formatos acessíveis, inclusive para a pessoa com deficiência, mediante solicitação do consumidor. (BRASIL, Lei 8.078, 1990) (grifo nosso)

Desse modo, a adequação das mensagens informativas de produtos e serviços torna-se indispensável, posto que a importância de um tratamento peculiar, diferenciado à pessoa com deficiência, tanto valoriza o seu poder de decisão, quanto resguarda a aplicação dos princípios da dignidade da pessoa humana e da isonomia.

Os Egrégios Tribunais de Justiça, incessantemente, manifestam-se acerca da abusividade resultante da falta de informação as pessoas com 
deficiência no liame das relações consumeristas, reprimindo tais omissões dos fornecedores de produtos e/ou serviços.

Nesse sentido, colaciona-se a seguinte ementa jurisprudencial, in litteris:

Apelações Cíveis. Direito Constitucional e Processual Civil. Relação de consumo. Demanda de índole coletiva proposta por associação que representa os interesses dos deficientes visuais no estado do Rio de Janeiro, almejando a elaboração de documentos bancários em braille e a remessa de extratos bancários nessa linguagem ao domicílio dos consumidores com a referida deficiência, além da reparação por danos morais. Pretensão cominatória fundada no princípio da isonomia e na necessidade de integração das pessoas deficientes ao meio social. Direito individual e social a ser respeitado pelo poder público e pela sociedade, a teor da lei $n^{\circ} 7.853 / 89$ e Decreto $n^{\circ} 3.298 / 99$. Aplicação do preceito de informação adequada e clara, nos termos do inciso III, do artigo $6^{\circ}$, da lei $n^{\circ} 8.078 / 90$. Integração da decisão recorrida para que a obrigação de fazer abranja a confecç̧ão de cartilhas com normas de condutas direcionadas aos prepostos da instituição financeira para o atendimento de clientes com a referida necessidade especial(...). Recursos parcialmente providos. (TJRJ - APL: 00502620520078190001 RJ 005026205.2007.8.19.0001, Relator: DES. FABIO DUTRA, Data de Julgamento: 14/05/2013, PRIMEIRA CAMARA CIVEL, Data de Publicação: 01/08/2013) (grifo nosso).

Com efeito, o Ministro do Superior Tribunal de Justiça, Excelentíssimo Senhor Doutor Ricardo Villas Bôas Cueva, no julgamento do Recurso Especial $n^{\circ} 1.520 .202$ (2013/0341665-9) - SÃO PAULO - em seu voto assinalou:

[...] A discussão abrange, em última análise, interesse público primário do Estado que deve garantir os direitos constitucionais da dignidade da pessoa humana, de segurança, igualdade e informação (art. $1^{\circ}$, III e $5^{\circ}$, caput, e XIV, da Constituição Federal). A perda da visão não deve afastar do mercado de consumo tais consumidores. Ao contrário, os fornecedores devem se adaptar a essa categoria de consumidores diferenciada, 
considerada hipervulnerável, dada a manifesta condição de fragilidade e hipossuficiência que os caracteriza. É incontestável que o portador de deficiência visual encontra maiores dificuldades do que o cidadão comum, daí a indispensabilidade de obter informações objetivas por meio de manual (braile), o que deve ser realizado de forma plena e segura, sob pena de the impor um inaceitável isolamento social. (...) o consumidor deficiente visual tem o direito de acesso às informações de todo produto ou serviço colocado no mercado (art. 31 do CDC), incumbindo aos fornecedores cumprir as determinações legais para que a perda da visão não signifique o fim da independência desses consumidores, cujas limitações não os impedem de alcançar uma vida plenamente produtiva e livre[...].

Portanto, vale dizer que o desenvolvimento de uma política de inclusão às pessoas com deficiência nas relações de consumo é medida cogente, uma vez que as normas protetivas da legislação consumerista devem ser efetivas quanto à mantença e defesa dos direitos fundamentais de cada indivíduo, preservando, assim, um tratamento digno para todos.

\section{CONCLUSÃO}

Tendo em vista os aspectos abordados, espera-se que seja compreendido que a pessoa com deficiência deve ter resguardado os seus interesses, como todo e qualquer ser humano, não podendo ficar aquém de relações atinentes ao convívio em sociedade, como o são as relações de consumo, na medida em que cabe aos fornecedores se prepararem e se adequarem a essa demanda de consumidores.

Dessa forma, o debate quanto aos direitos protetivos do consumidor deve respeitar o viés constitucional, especialmente quanto aos princípios da dignidade da pessoa humana e da isonomia, uma vez que se constata que as dificuldades de aplicação das normas protetivas são inerentes ao atual contexto do relacionamento fornecedor-consumidor.

Assim, as pessoas com deficiência merecem o devido tratamento para que sejam capazes de exercer seus direitos consumeristas, cabendo aos fornecedores ajustar seus produtos e serviços, bem como suas mensagens informativas, assegurando o equilíbrio e a boa-fé na relação contratual e, conseguintemente, as garantias fundamentais de todo cidadão. 


\section{REFERÊNCIAS}

ANDRIGUI, Fátima Nancy. A tutela jurídica do consumidor e o respeito à dignidade da pessoa humana. In: MIRANDA, Jorge; MARQUES DA SILVA, Marco Antônio (coord.). Tratado Luso-Brasileiro da dignidade humana. São Paulo: Quartier Latin, 2008.

ARAUJO, Luiz Alberto David. A proteção constitucional das pessoas portadoras de deficiência. Brasília: Coordenadoria Nacional para Integração da Pessoa Portadora de Deficiência, 1997. Disponível em: <http://www.luizalbertodavidaraujo.com.br/free_download_5.html >. Acesso em: 09 ago. 2015.

BRASIL. Decreto-Lei n 6949, de 25 de agosto de 2009. Promulga a Convenção Internacional sobre os Direitos das Pessoas com Deficiência e seu Protocolo Facultativo, assinados em Nova York, em 30 de março de 2007. Disponível em: < http://www.planalto.gov.br/ ccivil_03/_ato2007-2010/2009/decreto/d6949.htm>. Acesso em: 09 ago. 2015.

. Lei $\mathrm{n}^{\circ}$ 13146, de 6 de julho de 2015. Institui a Lei Brasileira de Inclusão da Pessoa com Deficiência (Estatuto da Pessoa com Deficiência). Disponível em: <http://www.planalto.gov.br/ccivil_03/_ Ato2015-2018/2015/Lei/L13146.htm>. Acesso em: 09 ago. 2015.

. Lei $\mathrm{n}^{\circ} 8078$, de 11 de setembro de 1990. Dispõe sobre a proteção do consumidor e dá outras providências. Disponível em: <http://www.planalto.gov.br/ccivil_03/Leis/L8078.htm>. Acesso em: 09 ago. 2015.

. Superior Tribunal de Justiça. Recurso Especial n 1.520.202 SP (20130341665-9). Relator: Des. Ricardo Villas Bôas Cueva, São Paulo, 12 de maio de 2015, T3 - Terceira Turma.

Tribunal de Justiça do Rio de Janeiro. Apelação $\mathrm{n}^{\circ}$ 
00502620520078190001 RJ (0050262-05.2007.8.19.0001). Relator: Des. Fabio Dutra. Rio de Janeiro, 14 de maio de 2013.

FEIJÓ, Alexsandro Rahbani Aragão. Direitos humanos e proteção jurídica da pessoa portadora de deficiência: normas constitucionais de acesso e efetivação da cidadania à luz da Constituição Federal de 1988. Brasília: Ministério da Justiça, Secretaria de Estado dos Direitos Humanos, 2002.

FERRAZ, Carolina Valença. Manual dos direitos da pessoa com deficiência. Carolina Valença Ferraz [et al.]. São Paulo: Saraiva, 2012. Outros autores e coordenadores: George Salomão Leite, Glauber Salomão Leite, Glauco Salomão Leite.

GAGLIANO, Pablo Stolzen. Novo curso de direito civil: direito das sucessões, v 7. Pablo Stolzen Gagliano, Rodolfo Pamplona Filho. São Paulo: Saraiva, 2014.

MARQUES, Claudia Lima e outros. Comentários ao Código de Defesa do Consumidor. São Paulo: Revista dos Tribunais, 2004.

MENDES, Gilmar Ferreira. Curso de Direito Constitucional. Gilmar Ferreira Mendes, Inocêncio Martires Coelho, Paulo Gustavo Gonet Branco. 4 ed. rev. e atual. São Paulo: Saraiva, 2009.

MORAES, Alexandre de. Constituição do Brasil interpretada e legislação constitucional. São Paulo: Atlas, 2002.

NUNES, Luiz Antônio Rizzato. Curso de Direito do Consumidor. São Paulo: Saraiva, 2005.

SILVA, José Afonso da. Curso de Direito Constitucional positivo. $20^{\circ}$ ed. rev. e atual. São Paulo: Malheiros, 2002. 